Department of Social Systems and Management

\author{
Discussion Paper Series
}

No. 1142

Resale Externality and Used Housing Market

by

Shinichiro Iwata and Hisaki Yamaga

January 2006

UNIVERSITY OF TSUKUBA

Tsukuba, Ibaraki 305-8573

JAPAN 


\title{
RESALE EXTERNALITY AND Used Housing Market
}

\author{
SHINICHIRO IWATA \\ Faculty of Economics, University of Toyama \\ 3190, Gofuku, Toyama, 930-8555, Japan \\ Phone: +81-76-445-6425, Fax: +81-76-445-6419 \\ E-mail: iwata@eco.toyama-u.ac.jp
}

\section{HiSAKI YAMAGA}

Graduate School of Systems and Information Engineering, University of Tsukuba

1-1-1, Tennoudai, Tsukuba, 305-8573, Japan

Phone: +81-29-853-5179, Fax: +81-29-855-3849

E-mail: yamaga@sk.tsukuba.ac.jp

January 18, 2006

\begin{abstract}
The selling prices of used houses may not fully reflect the maintenance spending of current owners when prospective buyers are unable to conduct a thorough inspection of houses offered for resale. This paper investigates how this resale externality problem affects the maintenance expenditures of homeowners. After considering both observable and unobservable repair expenses, the analysis shows that the resale externality reduces not only maintenance expenditures, but also household mobility. A treatment effects model is used to estimate the simultaneous relationship between mobility and maintenance in the Japanese resale housing market. The results indicate that the resale externality has a significant negative impact on maintenance expenditures.
\end{abstract}




\section{Introduction}

Prospective buyers of used houses cannot fully observe how home-sellers renovate and repair dwellings during their period of ownership. As a result, problems of adverse selection and moral hazard arise. ${ }^{1}$

Chinloy (1978) examines theoretically and empirically an adverse selection problem in the resale housing market. Chinloy (1978) shows that resale prices decline with time due to an increase in the population of "lemons" (i.e. houses that have been poorly maintained). Ultimately, all resale prices will approximate those of lemons and lemons will dominate the resale market. Harding, Miceli and Sirmans (2000) examine the moral hazard problem faced by homeowners. Because prospective buyers are unable to conduct a perfect examination of homes offered for sale, the selling prices of used houses do not fully reflect the current owner's repair expenses. Harding, Miceli and Sirmans (2000) refer to this as a resale externality. In turn, this externality creates a moral hazard: seller-owners do not attempt to repair any damage to the house. Using maintenance expenditures data from the American Housing Survey (AHS), Harding, Miceli and Sirmans (2000) attempt to find evidence of the resale externality. They hypothesize that the maintenance expenditures of homeowners who are planning to move and sell their dwellings are lower than those of homeowners who choose to stay because of the resale externality. However, no evidence was found of the resale externality. ${ }^{2}$ Harding, Miceli and Sirmans (2000) argue this is because the observable and cosmetic repairs required to mask serious housing problems outweigh the unobservable and substantial maintenance requirements.

Ben-Shahar (2004) argues that while the quality of housing is not perfectly observable, improvement and maintenance are verifiable. Thus, investing in improvement and maintenance before sale becomes a signal for better quality. In contrast to the literature discussed above, Ben-Shahar (2004) shows that excessive maintenance spending occurs to reduce the

\footnotetext{
${ }^{1}$ Knight, Miceli and Sirmans (2000) show that if the buyer requires, as part of the purchase agreement, the seller to make the repairs necessary to bring the house to a normal level of maintenance, the seller maintains the house before closing. In this case, the selling price represents the value of a normally maintained home. This is empirically proven with residential brokerage firm data from Stockton, California.

${ }^{2}$ While Boehm and Ihlanfeldt (1986) do not consider the resale externality, they also estimate the relationship between home improvement expenditures and predicted mobility. The coefficient of mobility in their model is insignificant with a positive sign, as in Harding, Miceli and Sirmans (2000).
} 
adverse selection problem. Accordingly, in practice both observable and unobservable forms of maintenance exist. Thus, we consider both observable and unobservable maintenance in the theoretical section, and examine the effects of the resale externality on these two types of maintenance.

One consideration, however, is that Harding, Miceli and Sirmans (2000) do not consider the moving decisions of homeowners. In contrast, Montgomery (1992) and Shear (1983) examine a utility maximization model where homeowners simultaneously decide to move and improve. ${ }^{3}$ Their model has a two-period structure, with second-period effects of the sale price on households' move and renovate decisions. ${ }^{4}$ They do not, however, deal with the resale externality. Because asymmetric information on maintenance may reduce the selling price in the used housing market, the resale externality is likely to have an impact on the mobility of homeowners. Thus, we are concerned with the effects of households' decision-making on their mobility under the resale externality.

Using the Japanese Housing Demand Survey (JHDS), this paper empirically examines these issues. This is especially important since problems with asymmetric information in the Japanese resale housing market are likely to be more acute than in, say, the U.S. According to the White Paper on Land, Infrastructure and Transportation in Japan (2003), the percentage of existing home sales in relation to overall home sales (overall home sales represent the total of new housing starts and existing home sales) is $76.1 \%$ in the U.S., $88.2 \%$ in the U.K., $71.4 \%$ in France, and just $11.8 \%$ in Japan. These figures suggest that the Japanese market is a more suitable context than the U.S. to examine resale externalities. Unfortunately, we cannot separate observable and unobservable maintenance. Thus, we use total maintenance expenditures as in previous studies. ${ }^{5}$ To measure the effect of the resale externality on housing maintenance, we follow the approach taken by Harding, Miceli and Sirmans (2000).

In addition, we consider the self-selection bias of the dummy variable indicating imminent sale. Employing the U.S. Annual Housing Survey, Shear (1983) uses a multinomial logistic

\footnotetext{
${ }^{3}$ Prospective home-buyers also have an option to improve their used house after purchase (Littlewood and Munro, 1997). However, we are not concerned with this.

${ }^{4}$ Rosen and Smith (1986) construct an aggregate model of sales and renovation activity based on the adjustment choice decision of homeowners to alter their housing consumption by moving or improving.

${ }^{5}$ Bogdon (1996) hypothesizes that there are differences in the determinants of the various categories of renovation and repair. Therefore, she estimates the determinants of renovation and repair expenditures separately for each of the nine different categories provided by the AHS.
} 
analysis to estimate the simultaneous relationship between housing maintenance and moving behavior. With the same data, Montgomery (1992) employs the Heckman two-stage method to control selectivity bias: the first stage estimates an ordered probit model where the homeowners' choices are defined as moving, doing nothing, and improving, and the second stage estimates an improvement expenditure equation. We apply the treatment effects model using full maximum likelihood. ${ }^{6}$ This model considers the endogenous problem of the homeowner's decision whether to move and sell the current dwelling in the future and maintenance expenditure. We include the estimated selling price deducted from the actual purchase price to measure the effect of the resale externality on household mobility. ${ }^{7}$ In addition, we obtain two types of alteration of existing housing units from the JHDS: one is rebuild, the other, remodel. We assume that remodeling is more likely to include observable maintenance than rebuilding, and use a bivariate probit model to examine the choice between resale of the current dwelling in the future and remodeling on the type of maintenance.

The remainder of the paper is organized as follows. Section 2 presents a theoretical model where homeowners choose either to move and resell the current dwelling or stay, making an optimal choice of maintenance expenditures under the resale externality. The data and empirical model are described in Section 3, along with the empirical results. Section 4 summarizes the main conclusions of the paper.

\section{The Model}

Consider a two-period model. In period 1, individuals choose the level of housing stock, the total maintenance expenditures $M$, and the composite good, $x$. Because we focus on maintenance spending, we assume that housing comprises a single unit. We assume that repair work, which an owner performs, is completed at the end of period 1 . Thus, the current level of maintenance does not affect housing wealth in period 1. The budget constraint of homeowners in period 1 is then $y=x+p-M$, where $y$ is the first-period income and $p$ is the purchase price of the single unit of housing wealth.

\footnotetext{
${ }^{6}$ Green (2003) provides further detail concerning the treatment effects model.

${ }^{7}$ The White Paper of Construction in Japan (1996) shows that $8.1 \%$ of owner-occupied households move each year in the U.S., whereas only $1.8 \%$ do so in Japan. Yamazaki (1999) suggests that this difference occurs because information on maintenance records is not well prepared in Japan. Hence, homeowner's efforts in housing maintenance do not impact on the selling price, and consequently, owner mobility is reduced.
} 
Assume that the present value of housing wealth $(w)$ in period 2 depends on maintenance expenditures undertaken in period 1 . Furthermore, housing wealth is assumed to be a function of two types of variables: $o$ and $u$, where $M \equiv o+u$. The variable $o$ represents observable (and verifiable) maintenance expenditures and the variable $u$ represents unobservable maintenance expenditures. ${ }^{8}$ Thus, housing wealth can be written as $w=w(o, u)$. We assume that both arguments increase housing wealth value at a decreasing rate. Thus $w_{o}>0, w_{o o}<0, w_{u}>0$, and $w_{u u}<0$. We denote the partial derivatives of $w(o, u)$ with respect to its argument as the marginal value. The sign of the cross-partial derivatives of $w(o, u)$ is evaluated as follows. If $o$ and $u$ are independent, then $w_{o u}=0$. We refer to this as case I. If $o$ and $u$ are complements (substitutes), then $w_{\text {ou }}>0(<0)$. Complements (substitutes) imply that a greater level of one argument increases (decreases) the marginal value of the other. We refer to these complements (substitutes) as case C (S).

Homeowners have two options in period 2: sell the housing or stay. Let us write the net benefit of the former, $\Phi$, and that of the latter, $\Psi$. Homeowners then choose the option that generates the higher net benefit, i.e., $\max \{\Phi, \Psi\}$.

Suppose that a two-period utility function has a simple additive form. If the owner continues to dwell in the same housing, then he or she obtains: ${ }^{9}$

$$
\Psi=x+w(o, u)+\psi
$$

where $\psi$ is the pecuniary (present) value of utility they can gain at his or her present location. ${ }^{10}$ After substituting for $x$ using the budget constraint in period 1, we have

$$
\Psi=y-p-o-u+w(o, u)+\psi .
$$

\footnotetext{
${ }^{8}$ The Housing Performance Indication System was established in 2000 by the Organization for Housing Warranty for the purpose of securing and enhancing the quality of dwellings. Initially, this was restricted to new residential housing, but was extended to existing houses in 2002. The performance indicators contained in this provision for newly-built houses include nine criteria or fields ((1) structural performance, (2) fire safety, (3) durability, (4) ease of maintenance and management, (5) energy efficiency, (6) air quality, (7) ratio of exterior openings to total wall area, (8) noise transmission, and (9) barrier free design) across 29 items. However, there are only 21 items in six fields that can be established for used houses because they cannot be inspected after construction. In addition, if the house did not have a warranty at the start of occupation, the number is further reduced to five fields with 12 items. Put simply, 17 of the total 29 items cannot be fully inspected for a house offered for resale.

${ }^{9}$ We do not include mortgage debt due to data limitations. In the U.S., Harding, Miceli, and Sirmans (2000) show that the risk of mortgage default, coupled with limited liability, creates a disincentive to optimally maintain the dwelling.

${ }^{10}$ We suppress housing stock as with Harding, Miceli and Sirmans (2000), and simply write the utility from housing as $w(o, u)$.
} 
When the owner chooses to move, we assume he or she sells the house in the used houing market. Resale externality problems, however, arise in the secondary market because prospective buyers of the house may have imperfect information about maintenance. As a result, the selling price of the used house does not fully reflect the previous owner's maintenance efforts. To introduce this in our model, we assume the following: the owner believes that buyers underestimate the input level of $u$ just $\frac{1}{\alpha}(\alpha>1)$ due to the resale externality. Thus, if the owner resells a house, he or she obtains:

$$
\Phi=y-p-o-u+w(o, v)+\phi
$$

where $v \equiv \frac{1}{\alpha} u$ and $\phi$ is the pecuniary (present) value they can gain at a new location. Eq. (2) implies that the owner obtains only $w(o, v)$ because $u$ is unobservable.

The optimal conditions for $o$ and $u$ in (1) become:

$$
\begin{aligned}
& w_{o}=1, \\
& w_{u}=1 .
\end{aligned}
$$

The equilibrium investment levels are denoted by $o^{*}$ and $u^{*} \cdot{ }^{11}$

The optimal conditions for (2) become:

$$
\begin{aligned}
w_{o} & =1, \\
\frac{1}{\alpha} w_{v} & =1 .
\end{aligned}
$$

We denote the equilibrium input levels in this case as $o^{R}$ and $u^{R}$.

The equilibrium investment levels are the same while $u$ is observable . That is, $o^{*}=o^{R}$ and $u^{*}=u^{R}$ if $\alpha=1$. Thus $\alpha>1$ shows the effect of the resale externality. Differentiating equations (3) and (4) with respect to $\alpha$, and applying Cramer's rule yields the following:

$$
\begin{gathered}
\Delta \frac{d o}{d \alpha}=-\frac{1}{\alpha} w_{v} w_{o v} \\
\Delta \frac{d u}{d \alpha}=v\left[\left(\frac{1}{\eta_{v v}}+1\right) w_{o o} w_{v v}-w_{o v}^{2}\right]
\end{gathered}
$$

\footnotetext{
${ }^{11}$ We assume that an interior solution exists for the first-order conditions. This is assumed to hold throughout the analysis. Thus, in our model homeowners choose some positive amount of maintenance. As an alternative, Montgomery (1992) uses the discontinuity and nonconvexity of the budget constraint to develop a model in which homeowners can choose not to make improvements.
} 
where $\Delta \equiv w_{o o} w_{v v}-w_{o v}^{2}$ and $\eta_{v v} \equiv v \frac{w_{v v}}{w_{v}}$. The notation $\eta_{v v}$ indicates the input elasticity of the marginal value losses, i.e., the percentage change in the marginal value on $v$ in response to a given percentage change in the input $v$, the sign of which is negative. The notation $\Delta$ is positive because we suppose that the second order condition for a maximum is satisfied. Eqs. (5) and (6) yield the following proposition:

Proposition 1 When the owner resells the house, the resale externality yields $(i) o^{*}=o^{R}$ in case $I, o^{*}>o^{R}$ in case $C$, and $o^{*}<o^{R}$ in case $S$, and (ii) if $\eta_{v v} \in(-1,0)$, then $u^{*}>u^{R}$ in case $I$, and if $\eta_{v v} \in\left(-\frac{w_{o o} w_{v v}}{\Delta}, 0\right)$, then $u^{*}>u^{R}$ in both case $C$ and case $S$.

In their empirical analysis, Harding, Miceli and Sirmans (2000) suggest that sellers have a tendency to make observable cosmetic repairs. However, the results of over-maintenance cannot be derived from their theoretical model because it only considers unobservable inputs. In contrast to their model, our model can derive over-maintenance on $o\left(o^{*}<o^{R}\right)$ when $o$ and $u$ are substitutes. Our model also deals with the problem of under-maintenance on $u$ $\left(u^{*}>u^{R}\right)$ due to the resale externality, as shown by Harding, Miceli and Sirmans (2000).

Next, let us examine the effect of the resale externality on total maintenance expenditures $M(M \equiv o+u)$. This is represented by

$$
\frac{d M}{d \alpha}=\frac{d o}{d \alpha}+\frac{d u}{d \alpha}
$$

If $\frac{d u}{d \alpha}<0$, then the resale externality reduces total maintenance expenditures in case $\mathrm{I}\left(\frac{d o}{d \alpha}=0\right)$ and case $\mathrm{C}\left(\frac{d o}{d \alpha}<0\right)$. Suppose case $\mathrm{S}\left(w_{o v}<0\right)$. In this case, $o$ is larger than optimal level in equilibrium, i.e., $\frac{d o}{d \alpha}>0$. Thus the resale externality has an ambiguous impact on total maintenance expenditures. Note that $\frac{1}{\alpha} w_{v}=w_{o}$ in equilibrium from the first-order conditions (3) and (4). Substituting this relation, (5), and (6) into the right-hand side in (7), we have the following:

$$
\Delta \frac{d M}{d \alpha}=v\left[\left(\frac{1}{\eta_{v v}}+1\right) w_{o o} w_{v v}-\left(\frac{1}{\eta_{o v}}+1\right) w_{o v}^{2}\right]
$$

where $\eta_{o v}$ is the cross-input elasticity of the marginal value, defined as $\eta_{o v} \equiv v \frac{w_{o v}}{w_{o}}$. The sign of $\eta_{o v}$ is negative in case S. If the right-hand side in (8) becomes negative, then we can conclude that total maintenance expenditures are reduced due to the resale externality, even in case S. Thus, we have the following: 
Lemma 1 If $\eta_{v v} \in\left(-\frac{w_{o o} w_{v v}}{\Lambda}, 0\right)$, then the resale externality yields under-investment on total maintenance expenditures even in case $S$, where $\Lambda=\Delta-\frac{w_{o v}^{2}}{\eta_{o v}}$.

Lemma 1 implies that $\frac{d M}{d \alpha}$ is more likely to be negative when $\eta_{v v}$ is less likely to be elastic ( $\eta_{o v}$ is more likely to be elastic). To interrupt lemma 1 more intuitively, let us restrict the interval of $\eta_{v v}$ and $\eta_{o v}$. Suppose $\eta_{o v}=-1$. Then, to satisfy the condition on lemma 1 , $\eta_{v v} \in(-1,0)$. The resale externality increase the marginal products $\left(w_{v}\right)$ because it evaluates $u$ at a lower point: the resale externality lowers $u$ just $\frac{1}{\alpha}$. This works at the direction where the amount of the $u$ is increased. Inelasticity of $\eta_{v v}$, however, implies this effect is small. Thus under-maintenance on $u$ occurs in this case, and consequently the sign of $\frac{d M}{d \alpha}$ becomes negative under $\eta_{o v}=-1$. Suppose next $\eta_{v v}=-1$. Then, to satisfy the condition on lemma $1, \eta_{o v}<-1$. Elastic $\eta_{o v}$ implies that when the owner increases $o$, the loss from investment on $u$ becomes large. This induces large under-maintenance on $u$, and as a consequence in this case, the level of under-investment on $u$ outweighs over-investment on $o$.

The efficient transfer condition depends on $\Phi$ and $\Psi$. If $\Phi$ is larger than $\Psi$, the owner decides to move and sell the house. Otherwise, the owner remains. The efficient transfer condition does not depend on the value of housing $w$ if $\alpha=1$. Because parameter $\alpha$ has an impact on $\Phi, \alpha>1$ shows the effect of the resale externality on owners' mobility. Differentiating $\Phi$ with respect to $\alpha$ and using (3) and (4) we have:

$$
\frac{d \Phi}{d \alpha}=-v
$$

This implies that the resale externality reduces the gains from transfer, from which we obtain the following proposition:

Proposition 2 The probability of transfer decreases under the resale externality.

\section{Empirical Analysis}

\subsection{The Data}

We use the 2003 Japanese Housing Demand Survey (the JHDS) data to test the model. Conducted by the Japanese Ministry of Land, Infrastructure and Transport every five years, the JHDS collects micro-level cross-sectional data on 100,000 households. In practice, we 
cannot directly estimate $o$ and $u$. However, the JHDS does ask households to report total maintenance expenditures $M$ made in the last five years 1999-2003. We use only those households that respond to this question. Moreover, we limit the sample to single-family detached owner-occupied housing, because condominiums and apartment buildings have the potential to create a free-rider problem in the sense that owners have an incentive to undermaintain common areas. Screening the data for complete information on the selected variables produces a sample of 3,195 observations of homeowner expenditures on maintenance.

\subsection{Empirical Model of Maintenance Expenditures}

We follow the approach taken by Harding, Miceli and Sirmans (2000) to capture the effect of the resale externality on maintenance. That is, we estimate the following maintenance expenditures equation for the homeowner $i$ :

$$
M_{i}=X_{i} b+a R_{i}+e_{i}
$$

where $X_{i}$ are housing and household trait vectors, $R_{i}$ is the indicator of imminent sale and takes the value of one if the homeowner intends to sell the current dwelling (hereafter resale dummy), $b$ and $a$ are coefficients, and $e_{i}$ is the error term. ${ }^{12}$ In the sample, 45 households responded that they would resell their dwelling in the future. The sign of $a$ captures the impact of the resale externality. The predicted sign is ambiguous, because over-maintenance on $o$ occurs in case S. The sign becomes negative, however, when $\eta_{v v}$ is more likely to be inelastic ( $\eta_{o v}$ is more likely to be elastic) even in case $\mathrm{S}$ from lemma 1.

Table 1 presents summary statistics for the main variables included in $X_{i}$. We use the size of the structure (site area measured by square meter, lot size, and number of rooms, room), the year when the dwelling was built, construction year, and construction material, for housing characteristics. Note that if a house was extended or rebuilt, and if the new floor space was more than half of the total floor space of the house following extension or rebuilding, the construction year equates to the extension or rebuilding year in the JHDS. Construction material is classified into the following three categories: buildings whose main

\footnotetext{
${ }^{12}$ Harding, Miceli and Sirmans (2000) include zero maintenance expenditures, and use both OLS and Tobit as estimation methods. Because the JHDS is cross-sectional data, in our model maintenance expenditures before 1999 are zero, even if investment actually takes place. Thus, only homeowners with nonzero maintenance expenditures are included in the sample.
} 
frames are made of wood (this is the reference group); buildings whose main frames are made of ferroconcrete and steel ferroconcrete; steel reinforced concrete (SRC); and others. We also include as homeowner characteristics the total annual income before tax earned by all household members (income), the number of household members (household size), the age of the household head (age), and the year of relocation to the present dwelling (move-in year). Maintenance, lot size, member, and age are continuous variables. In the estimation stage, we take the natural logarithmic transformation for these variables. Construction year, income, and move-in year are classified into 13 different categories in the JHDS, from 1 (the oldest or the lowest) to 13 (the latest or the highest). We add these in ascending order to the explanatory variables in Eq. (10). Three geographical categories are included, comprising: twenty-three Tokyo wards (Tokyo); twelve major cities outside Tokyo (large city); and all other areas (reference).

Importantly, $R_{i}$ (the resale dummy) is endogenous because households decide whether or not they will move and sell. Hence, we employ the treatment effects model using full maximum likelihood to control for this self-selection bias. Moreover, from (9) or Proposition 2 , the resale externality reduces household mobility because it lowers the price of a used house. Thus, transfer and resale depend on the expected price of housing when the owner-occupier intends to sell. To estimate the predicted value of a house if it were sold on the resale housing market, we employ a hedonic price of a single-family used house purchased in the period 1999-2003 drawn from the JHDS (314 households in the sample). Let $W_{j}$ be the price paid on a used house with housing characteristics $H_{j}$, and $\hat{\gamma}$ is the OLS estimated coefficient from $W_{j}=H_{j} \gamma{ }^{13}$ Then $\hat{W}_{i}=H_{i} \hat{\gamma}$ gives the predicted price if the house were sold in the resale housing market.

We estimate a following specification for resale choice:

$$
\begin{aligned}
& R_{i}^{*}=Z_{i} \beta+\delta \hat{W}_{i}+\varepsilon_{i}, \\
& R_{i}=1 \text { if } R_{i}^{*}>0,
\end{aligned}
$$

where $R_{i}^{*}$ is an unobserved latent variable, $Z_{i}$ is household trait vectors, $\beta$ and $\delta$ are coeffi-

\footnotetext{
${ }^{13}$ We specify a log-linear model with the natural log of the purchase price. The variables include lot size, room, construction year, construction material, commuting distance, the presence of insulated window sashes, the condition of inclination, whether the dwelling has been made barrier-free out of consideration for the elderly, and geographical dummy variables.
} 
cients, and $\varepsilon_{i}$ is the error term. We expect that the resale externality lowers the price of a used house, and consequently reduces household mobility. Thus, we expect $R_{i}^{*}$ to be positively related to the predicted price. The degree of dissatisfaction of the dwelling (DS dwelling) and neighborhood (DS neighborhood) are included in $Z_{i}$. The JHDS asks households to report their degree of satisfaction with the dwelling and neighborhood. Their responses are classified into 4 different categories: 1 . satisfied, 2. fairly satisfied, 3. fairly dissatisfied, and 4. very dissatisfied: the larger the number, the greater the degree of dissatisfaction. We add this ascending index to the explanatory variables when we estimate (11). We expect $R_{i}^{*}$ to be positively related to the degree of dissatisfaction.

The distribution of $\left(\varepsilon_{i}, e_{i}\right)$ is assumed to be bivariate normal, with $\left[0,0,1, \sigma_{e}, \rho\right]$. The correlation $\rho$ becomes nonzero when $\varepsilon_{i}$ and $e_{i}$ are correlated.

\subsection{Estimation Results}

Table 2 reports the empirical results. Before discussing the effect of the resale externality on the simultaneous relationship between household mobility and maintenance expenditures, we briefly refer to another control variable. Lot size and room have a statistically positive significant on maintenance expenditures, i.e., a larger dwelling requires more maintenance. As expected, the degrees of dissatisfaction with the dwelling and neighborhood have a statistically significant positive impact on imminent sale. High income homeowners spend more on maintenance, and are more likely to move and sell their dwelling. In contrast, households with more members spend less on maintenance, and are less likely to move and sell the dwelling. The longer a household has occupied its current dwelling, the more it spends on housing maintenance, and the less likely to sell. The former result is inconsistent with Montgomery (1992). Homeowners with longer duration of occupation are less likely to face the resale externality problem, and consequently they obtain the true benefit from their maintenance expenditures. Thus, maintenance expenditure in our model increases with duration. Construction year has a positive and significant coefficient in the maintenance expenditures equation. This implies that homeowners with older houses spend less on housing maintenance. The result lies at odds with the results presented in Harding, Miceli and Sirmans (2000), and Montgomery (1992). This may be because the definitions of construction year 
differ between the JHDS and the AHS. As discussed, the year of construction in the JHDS can change following extensive renovation. The age, construction material and geographical dummies are all insignificant.

We find that the predicted price is positively related to mobility. Because the resale externality lowers the selling price of the used house, household mobility would be lowered by the resale externality. However, the coefficient is insignificant.

The hypothesis that selection bias in not present $(\rho=0)$ is rejected at the $1 \%$ significance level. As expected, there is correlation between mobility and maintenance expenditures. After correction for selection bias, the resale dummy has a large significant negative impact on total maintenance expenditures. Homeowners who intend to sell the current dwelling spent $75 \%$ $(\exp (-1.39)-1=-0.75)$ less than those intending to remain in the dwelling. This suggests that resale externalities cause serious damage to the used housing market in Japan.

\subsection{Rebuilding and Remodeling}

Harding, Miceli and Sirmans (2000) hypothesize that sellers have a tendency to make observable cosmetic repairs. Our model also predicts this outcome. Unfortunately, the treatment effects model presented in the previous section cannot capture this tendency. To capture this, we estimate a bivariate probit model which takes into account the discrete choice of maintenance activities. But as discussed, $o$ and $u$ cannot be gathered from the JHDS. The JHDS does, however, ask households to choose one category from three different types of maintenance, i.e., extend, rebuild, and remodel, done in the past five years. Extend is work to increase the floor area of an existing dwelling. Rebuild is work to demolish part of a dwelling, and build again; e.g. rebuilding a kitchen, a toilet, and a bathroom. Remodel is work to repair, change, or renovate an existing dwelling, including remodeling the interior and changing the roofing. All categories will include both $u$ and $m$. We, however, suppose that both extend and rebuild are more likely to include unobservable maintenance than remodeling.

In the estimation below, extend and rebuild observations are combined into a single category. The dependent variable used in the probit analysis is a dummy variable set equal to one if households choose to remodel $(R M)$ and zero otherwise. In the sample, 34.5 percent are rebuild decisions, and 65.5 percent are remodel decisions. We replace Eq. (10) with: 


$$
\begin{aligned}
R M_{i}^{*} & =X_{i} B+A R_{i}+\xi_{i} \\
R M_{i} & =1 \text { if } \quad R M_{i}^{*}>0
\end{aligned}
$$

where $R M_{i}^{*}$ is an unobserved latent variable, $B$ and $A$ are coefficients, and $\xi_{i}$ is the error term. The sign of $A$ captures the impact of the resale externality. The predicted sign is positive when the rental externality has a tendency to make observable renovation. The distribution of $\left(\varepsilon_{i}, \xi_{i}\right)$ is assumed to be bivariate normal, with $[0,0,1,1, \lambda]$, where again $\varepsilon_{i}$ is the error term of Eq. (11), and $\lambda$ is the correlation coefficient.

Table 3 shows the results. The hypothesis that selection bias in not present $(\lambda=0)$ cannot be rejected in this case. We obtain a positive and significant effect of resale dummy. This suggest that homeowners who intend to sell the dwelling in the future choose to remodel (which is more likely to include observable maintenance than rebuild) than those who intend to stay. This finding is consistent with Harding, Miceli and Sirmans (2000).

\section{Conclusions}

In the paper, we investigate the effect of the resale externality on mobility and maintenance expenditures. Our main conclusions are as follows. In the theoretical part of the paper, we develop a model in which homeowners invest both observable and unobservable maintenance expenditures, and simultaneously choose whether to sell the dwelling or stay. We show that the resale externality reduces total maintenance expenditures when the input elasticity of marginal value is sufficiently small, because the under-maintenance of unobservable maintenance in this case becomes large. We also show that the resale externality always reduces mobility. In the empirical part of the paper, using data from the 2003 Housing Demand Survey of Japan we use a treatment effects model that confirms these theoretical predictions. After correcting for selection bias, we find that homeowners who intend to sell the dwelling in the future spend $75 \%$ less than those who intend to stay. That is, evidence for a negative resale externality exists in the Japanese used housing market. We also find that the resale externality is likely to reduce mobility, but to an insignificant extent. In addition, using a bivariate probit model we find that homeowners who are planning to sell the dwelling in the 
future have a tendency to undertake observable maintenance in contrast to those planning to stay.

\section{Acknowledgement}

Earlier versions of this paper were presented at the Applied Regional Science Conference in Kitakyushu, the Urban Economics Workshop in Tokyo, the Annual Conference of the Japanese Economic Association in Kyoto, the Asian Real Estate Society International Conference in Sydney, and the Annual Conference of the Association of Urban Housing Sciences in Tsukuba. The authors would like to thank Yoshihisa Asada, Takako Idee, Tatsuya Ishikawa, Yoshitsugu Kanemoto, Yoko Moriizumi, Kazuyuki Nakamura, Takatoshi Tabuchi and participants in these conferences and workshops for their valuable comments. All remaining errors are the sole responsibility of the authors. This research was supported by MEXT.KAKENHI (15730116).

\section{References}

Ben-Shahar, D. 2004. Productive Signaling Equilibria and Over-Maintenance: An Application to Real Estate Markets. Journal of Real Estate Finance and Economics 28(2/3): $255-271$.

Boehm T. P. and K. R. Ihlanfeldt. 1986. The Improvement Expenditures of Urban Homeowners: An Empirical Analysis. AREUEA Journal 14(1): 48-60.

Bogdon, A. S. 1996. Homeowner Renovation and Repair: The Decision to Hire Someone Else to Do the Project. Journal of Housing Economics 5(4): 323-350.

Chinloy, P. 1978. Depreciation, Adverse Selection and Housing Markets. Journal of Urban Economics 5(2): 172-187.

Green, W.H. 2003. Econometric Analysis. 5th ed. Prentice Hall: New Jersey.

Harding, J., T. J. Miceli and C. F. Sirmans. 2000. Do Owners Take Better Care of Their Housing Than Renters? Real Estate Economics 28(4): 663-681.

Knight, J. R., T. J. Miceli and C. F. Sirmans. 2000. Repair Expenses, Selling Contracts and House Prices. Journal of Real Estate Research 20(3): 323-336. 
Littlewood, A. and M. Munro. 1997. Moving and Improving: Strategies for Attaining Housing Equilibrium. Urban Studies 34(11): 1171-1787.

Montgomery, C. 1992. Explaining Home Improvement in the Context of Household Investment in Residential Housing, Journal of Urban Economics 32(3): 326-350.

Rosen, K. T. and L. B. Smith. 1986. The Resale Housing Market. AREUEA Journal 14(4): $510-524$.

Shear, W. B. 1983. Urban Housing Rehabilitation and Move Decisions, Southern Economic Journal 49(4): 1030-1052.

Yamazaki, F. 1999. An Economic Analysis of Land and Housing Markets in Japan (in Japanese). University of Tokyo Press: Tokyo. 
Table 1 Mean (Frequency/Mode) of variables

\begin{tabular}{lc}
\hline Variable & Mean \\
\hline Maintenance $(10,000$ yen $)$ & 483.0 \\
\% Resale & 1.4 \\
Lot size $\left(\mathrm{m}^{2}\right)$ & 533.8 \\
Room & 6.7 \\
Construction year & $1971-1980$ \\
\% SRC & 4.4 \\
\% Others & 3.7 \\
Income (10,000 yen) & $500-600$ \\
Household size & 3.7 \\
Age & 55.7 \\
Move-in year & $1971-1980$ \\
\% Tokyo & 1.6 \\
\% Large city & 8.0 \\
& \\
Number of observations & 3,195 \\
\hline
\end{tabular}


Table 2 Maintenance expenditures and resale choice estimation results

\begin{tabular}{|c|c|c|c|}
\hline Variable & Coefficient & & Z-statistics \\
\hline \multicolumn{4}{|c|}{ Maintenance expenditures } \\
\hline Intercept & $2.61^{* * *}$ & & 16.4 \\
\hline Resale & $-1.39^{* * *}$ & & -5.2 \\
\hline Lot size & $0.0004^{* *}$ & & 2.1 \\
\hline Room & $0.08^{* * *}$ & & 8.6 \\
\hline Construction year & $0.05^{* * *}$ & & 4.9 \\
\hline SRC & 0.004 & & 0.1 \\
\hline Others & -0.06 & & -0.7 \\
\hline Income & $0.03^{* * *}$ & & 5.4 \\
\hline Household size & $-0.04^{* * *}$ & & -3.0 \\
\hline Age & 0.003 & & 1.4 \\
\hline Move-in year & $-0.06^{* * *}$ & & -5.4 \\
\hline Tokyo & -0.01 & & -0.1 \\
\hline Large city & 0.02 & & 0.3 \\
\hline \multicolumn{4}{|l|}{ Resale choice } \\
\hline Intercept & $-4.68^{* * *}$ & & -3.6 \\
\hline Predicted price & 0.21 & & 1.0 \\
\hline DS dwelling & $0.37^{* * *}$ & & 4.4 \\
\hline DS neighborhood & $0.19^{* *}$ & & 2.3 \\
\hline Income & $0.04^{* *}$ & & 2.1 \\
\hline Household size & $-0.13^{* * *}$ & & -2.7 \\
\hline Age & -0.01 & & -1.0 \\
\hline Move-in year & $0.12^{* * *}$ & & 3.6 \\
\hline$\rho$ & 0.56 & & \\
\hline$\sigma_{e}$ & 0.99 & & \\
\hline LR test $(\rho=0)$ & & 8.8 & \\
\hline Log-likelihood & & $-4,656.3$ & \\
\hline Number of observations & & 3,195 & \\
\hline
\end{tabular}


Table 3 Remodel choice and resale choice estimation results

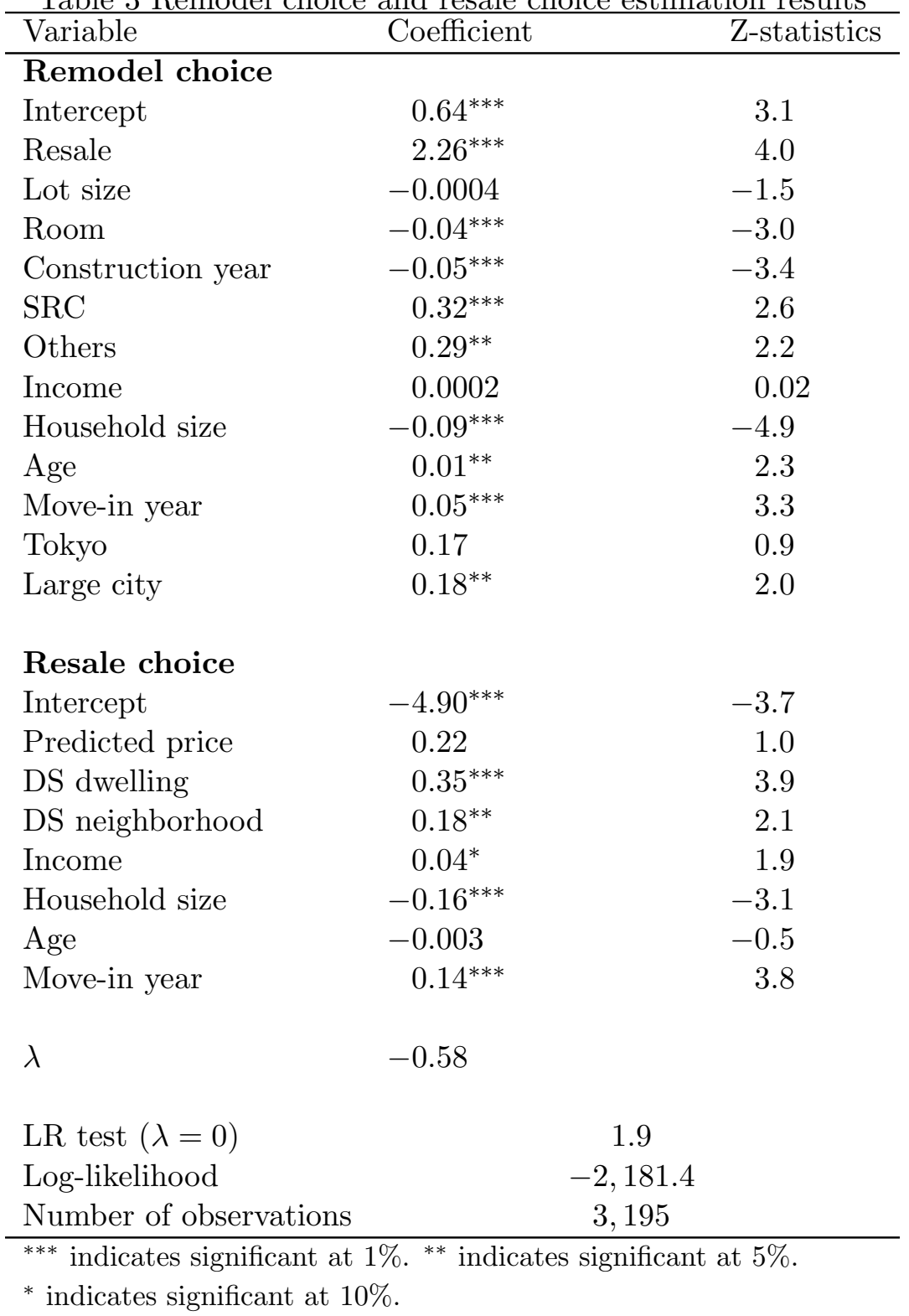

